This document is published in:

Review of Economic Dynamics (2004), 7 (2), 494-518.

DOI: http://dx.doi.org/10.1016/j.red.2003.09.005

(C) 2003 Elsevier Inc. 


\title{
Costly capital reallocation and energy use
}

\author{
Antonia Díaz, ${ }^{\mathrm{a}, *}$ Luis A. Puch, ${ }^{\mathrm{b}}$ and María D. Guilló ${ }^{\mathrm{c}}$ \\ a Department of Economics, Universidad Carlos III, 28093 Getafe Madrid, Spain \\ ${ }^{\mathrm{b}}$ Department of Economics, Universidad Complutense de Madrid, and ICAE, 28223 Madrid, Spain \\ c Department of Economics, Universidad de Alicante, Ap. Correos 99, E-03080 Alicante, Spain
}

\begin{abstract}
In time series data, energy use does not change much with energy price changes. However, energy use is responsive to international differences in energy prices in cross-section data across countries. In this paper we consider a model of energy use in which production takes place at individual plants and capital can be used either to directly produce output or to reduce the energy required to run the plant. We assume that reallocating capital from one use to another is costly. This turns out to be crucial for the quantitative properties of the model to be in conformity with the low short-run and high long-run elasticities of energy use seen in data.
\end{abstract}

(c) 2003 Elsevier Inc. All rights reserved.

JEL classification E22; E23; Q43

Keywords: Energy price; Energy use; Capital reallocation; Number of plants

\section{Introduction}

There are two salient features of data on energy use and energy prices. On the one hand, in time series data, energy use is not very responsive to energy price changes whereas energy expenditure varies very much (e.g., Berndt and Wood, 1975). On the other hand, in cross-section data across countries, energy use is very responsive to international differences in energy prices (e.g., Griffi and Gregory, 1976; Pindyck, 1991). In addition, there is a long lasting debate about the nature of the reallocation frictions that inf uence the aggregate response to energy price changes (cf. Davis and Haltiwanger, 1999). Do the

* Corresponding author.

E-mail address: andiaz@eco.uc3m.es (A. Díaz). 
frictions mainly involve labor or capital reallocation? In this paper we consider a model of energy use to account for the short-run and long-run features aforementioned and in which the main channel of transmission of energy price changes is capital reallocation. Our model is a version of the neoclassical growth model augmented with a second type of physical capital that acts purely as an energy saving device. We interpret this capital good as induced energy-saving innovation and we will call it energy saving capital. ${ }^{1}$

There are several studies on the effect of changes in energy prices on aggregate variables that also focus their attention on the capital channel. For instance, Pindyck and Rotemberg (1983) build a model in the neoclassical tradition. In their model, capital and energy are highly complementary and capital is subject to adjustment costs. The response to an energy price shock predicted by their model is a sharp reduction in energy use which limits fl ctuations in energy expenditure together with a big rise in the capital-energy ratio. As for the long-run behavior of the aggregates, persistent international differences in energy prices lead to large international differences in energy use and, due to the complementarity between capital and energy, they imply large differences in output. Just the opposite to what the data show.

Atkeson and Kehoe (1999) depart from the neoclassical framework and analyze energy intensity choice in a putty-clay model in which a large variety of types of capital goods are combined with energy in different $f$ xed proportions. In their setup, a more eff cient capital good is that which needs fewer units of energy per unit of capital. Using a more eff cient type has a cost, however; gross production per unit of capital is lower the more eff cient the type is. Furthermore, they assume that gross investment in each type of capital must be nonnegative. Therefore, in the short run, there is no way to substitute existing capital and energy. Over time, new capital goods embodying a different energy intensity can be installed so that, in the long run, energy use is elastic with respect to the energy price. This approach is appealing but somewhat extreme. Indeed, in their model, the capital-energy ratio adjusts too slowly compared to what we observe in data. Nevertheless, in the long run, the response of capital and output to permanent differences in energy prices is not too large. ${ }^{2}$

Atkeson and Kehoe's (1999) main message is that short-run complementarity between capital and energy is needed to account for the time series behavior of energy use and energy expenditure. As these authors, we build a model that has this feature. To do so, we extend Cooley et al. (1995) theoretical framework and assume that production takes place in plants. This allows us to obtain complementarity at the aggregate level from quasi-f xed factors at the plant level, and as a side product we obtain implications about changes in capacity utilization. Thus, as in Atkeson and Kehoe (1999), we assume that there is a

\footnotetext{
${ }^{1}$ Newell et al. (1999) test Hicks' induced innovation hypothesis that states that rising energy prices should have induced energy-saving innovation. They fin evidence that energy prices have affected the energy eff ciency of models of air conditioners and gas water heaters available on the market over the last four decades.

${ }^{2}$ Finn (1996) and Kim and Loungani (1992) also build models for energy use but their main focus is to improve the predictions of the standard real business cycle model. Hamilton (1988) and Davis and Haltiwanger (1999) analyze the labor market reallocation effects of energy price shocks. See Rotemberg and Woodford (1996) for a model of energy use that incorporates imperfect competition, and Sakellaris (1997) for a vintage approach to address the link between shocks to factor prices and f rm prof tability.
} 
f xed energy requirement, here at the plant level, that cannot be changed in the short run. Differently from them, we neither assume a large number of capital goods nor we restrict our analysis to equilibria in which all capital is fully utilized. We assume that plants are exante identical and differ according to an idiosyncratic technology shock. Capital installed in a plant has two uses: one is directly productive, and the other is to reduce the energy required to run the plant. Thus, for convenience, we will talk about two types of capital: productive capital and energy saving capital. We should think about the latter as any device that reduces energy use, as adjustable speed motors, or what Doms and Dunne (1993) call advanced manufacturing technologies (AMTs). ${ }^{3}$ These authors use data on energy use per unit of output at the plant level for plants built earlier than in 1989. They estimate that plants that use three to f ve AMTs use 13.8 percent less energy per unit of output than plants that use none. They also fnd that plants built between 1972 and 1983, the period right after the oil shocks, use 12.6 percent less energy than the youngest plants in the sample. In our model we abstract away from heterogeneity in energy eff ciency across plants but retain the main implication of Doms and Dunne (1993): investment in energy saving capital varies with energy prices. Nevertheless, we assume that investment in energy saving capital is subject to adjustment costs. The existence of adjustment costs implies that energy use reacts very slowly to energy price changes since reallocating capital from its productive use to its energy saving use (converting productive capital into energy saving capital) as well as undertaking new investment in energy saving capital are costly. ${ }^{4}$ Clearly, though, this specificati $n$ will leave open the channels for capital and energy to be substitutable in the long run.

In addition to the fi ed energy requirement, a fi ed number of workers is also needed to operate the plant and the marginal product of additional workers beyond this number is zero. A particular plant is operated if, given its realized technology shock and the realized energy price, it is able to produce enough output to cover its labor and energy costs. Thus, in equilibrium, some plants will operate and others will not and so, capacity utilization rate will vary with changes in energy prices. The number of plants may vary over time. Nevertheless, we assume that the number of plants cannot be changed readily to accommodate fluctuation in energy prices. Creating a plant takes time. We capture this idea assuming that capital is already allocated to the plant before the energy price and the idiosyncratic technology shock are known. Also, it is worth noting that value added in our framework has a ready representation as a constant returns to scale function of aggregate production factors. Consequently, we maintain our work within the neoclassical framework.

We evaluate the empirical performance of our model on US data and compare it to the results delivered by the Atkeson and Kehoe's (1999) putty-clay model. To do this, we simulate both models feeding in the data on the energy price to obtain predictions for the time paths of energy use, energy expenditure, capital and output. We $f$ nd that the time-

\footnotetext{
3 These AMTs refer, for instance, to computer aided design, fl xible manufacturing systems, computers used on factory foor, etc.

${ }^{4}$ Newell et al. (1999) report that "major tooling and redesign changes to incorporate energy-saving design options in models of heat pumps and air-conditioners require lead times of about 1.5-2 years for a single model and longer for an entire line. A typical cycle for introducing new appliance models can be three years."
} 
series behavior of energy use and energy expenditure in our model economy is very similar to that seen in data. Our fndings are in line with those reported in Atkeson and Kehoe's (1999) putty-clay model, but we improve their results on the behavior of the energy-capital ratio. In our model an energy price increase is followed by a reduction in the number of operating plants in the short run, which amounts to a fall in the capacity utilization rate. This is followed by a decrease in the number of plants. Energy saving capital adjusts very slowly and, therefore, energy use does not change very much with energy prices. As a result, energy expenditure fuctuates very much. The energy-capital ratio moves as in the data, whereas this ratio in the Atkeson and Kehoe's (1999) putty-clay model clearly moves too little and lagging that in the data. The reason for this is that the putty-clay framework imposes too strong restrictions to the substitution of energy for capital in the short run. This would have important consequences if, for instance, we want to study the mediumterm aggregate response to energy taxes, the welfare effects of an energy price increase or the business cycle properties of the main aggregates. Consequently, we consider our model specif cation a promising tool for analyzing the importance of energy price shocks and the channels through which they drive economic fuctuations.

As we have mentioned, capacity utilization rate in our model varies with the energy price. In particular, our model is able to account for the observed changes in capacity utilization, specially during the period 1975-1985. This result is in line with the f ndings reported by Bresnahan and Ramey (1993). They estimate that 65 percent of the output variance for the period 1972-1983 was due to capital reallocation induced by the oil shocks.

To analyze the response of our model to cross-section differences in energy prices we conduct the following experiment: we consider the effect on energy use and output of an energy tax that leads to a doubling of energy prices. We $f$ nd that a doubling of the energy price leads to a drop in energy use roughly of 30 percent, whereas it implies a 2.60 percent fall in long-run output. The latter number is comparable to that estimated by Goulder (1992, 1993, 1995) and Jorgenson and Wilcoxen (1993). It is smaller than that found by Atkeson and Kehoe (1999), ref ecting the difference between their framework and our own.

The rest of the paper is organized as follows: Section 2 describes the economic environment and the social planner's problem. Section 4 reviews the calibration of the model economy, Section 4 discusses the results, and Section 5 concludes.

\section{The model economy}

In this section we describe the environment. As we have said in the Introduction, we build upon Cooley et al. (1995) theoretical framework and we introduce energy as an additional production factor.

We will assume that energy is entirely bought in an international market at an exogenously given price $p_{t}$. Therefore, from the point of view of the economic agents, the energy price follows a stochastic process. We assume that there is no international borrowing and lending. In absence of an international credit market we can think of the price of energy as given by nature. This implies that, under market completeness, the 
second welfare theorem applies and, therefore, we can restrict our attention to eff cient allocations.

In Appendix B we provide a defi ition of competitive equilibrium for this model economy.

\subsection{Technology, measure of plants, and timing}

\subsubsection{Technology}

Production of the unique $\mathrm{f}$ nal good is carried out at a continuum of autonomous plants with measure $m_{t}$ and indexed by a productivity parameter, $s_{t}$. Output is produced with capital, labor and energy. One worker is required to operate the plant and the marginal productivity of additional workers beyond one is zero. ${ }^{5}$ There are two uses for capital. When capital is used directly to produce output we call it productive capital and denote it as $k_{t}$. When capital is used to reduce the energy required to run the plant we call it energy saving capital and denote it as $a_{t}$. Productive capital is combined with energy and labor to produce the $\mathrm{f}$ nal good. The proportion in which productive capital and energy are combined depends on the amount of energy saving capital used. Specif cally, we assume that the ratio productive capital to energy, $k_{t} / e_{t}$, used in the plant cannot exceed the proportion $1 / \gamma$ of the amount of energy saving capital. Thus, the amount of energy used in the plant should satisfy

$$
\frac{k_{t}}{e_{t}} \leqslant \frac{1}{\gamma} a_{t}, \quad \gamma>0 .
$$

This specif cation implies that a plant can use many different production processes that differ in their energy intensity use, measured by its productive capital-energy ratio. A more eff cient technology is one which has a lower energy intensity use. Adopting a more eff cient technology requires a higher level of energy saving capital. We should think of energy saving capital as any engine or appliance that reduces the energy required to run a plant.

The output produced by a plant with $k_{t}$ units of productive capital, $a_{t}$ units of energy saving capital, $d_{t}$ workers and $e_{t}$ units of energy is given by

$$
y_{t}= \begin{cases}\left(z+s_{t}\right) B k_{t}^{\theta} h\left(s_{t}\right) & \text { if } d_{t} \geqslant 1 \text { and } e_{t} \geqslant \gamma k_{t} / a_{t}, \\ 0 & \text { otherwise, }\end{cases}
$$

where $s_{t}$ is a plant specif c technology shock assumed to be independent of and identically distributed across time and plants. We assume that $s_{t}$ is uniformly distributed in the interval $[-\sigma, \sigma]$. The function $h\left(s_{t}\right)$ represents the number of hours the plant is operated and it is restricted to either be equal to $h_{0}>0$ or zero. The parameters $z$ and $\theta$ are both positive, with $\theta \in(0,1){ }^{6}$ The scale parameter $B$ is greater than zero. Plants are established by renting productive and energy saving capital from households.

\footnotetext{
5 This normalization does not affect the results.

${ }^{6}$ An economy wide technology shock could be introduced by using a random variable $z t$ instead of parameter $z$ as in Cooley et al. (1995). This exceeds the scope of this paper notwithstanding.
} 
Another technology that would deliver equivalent results to the one described above is the following: creating the plant amounts to installing $k_{t}$ units of productive capital and $a_{t}$ units of energy saving capital. The technology is

$$
\left(z+s_{t}\right)\left(k_{t}^{1-2 \phi} z_{e t}^{\phi} a_{t}^{\phi}\right)^{v} z_{d t}^{1-v} h\left(s_{t}\right)
$$

where $z_{e t}$ denotes services of energy and should be equal to $\min \left\{e_{t}, \gamma k_{t} / a_{t}\right\}, z_{d t}$ denotes labor services and should satisfy $\min \left\{d_{t}, 1\right\}$. Therefore, optimally, $e_{t}=\gamma k_{t} / a_{t}$ and $d_{t}=1$. Then introducing both constraints in (3) we obtain

$$
\left(z+s_{t}\right) \gamma^{\phi v} k_{t}^{(1-\phi) v} h\left(s_{t}\right),
$$

which is analogous to Eq. (2).

\subsubsection{Timing of decisions at the plant level}

Any prospective plant must choose the amount of capital to be installed in the plant before the energy price and the idiosyncratic shocks are known. Thus, the manager chooses $k_{t}$ and $a_{t}$ given the aggregate stock of capital, $K_{t}$ and $A_{t}$. After this decision has been made, the energy price is known and right after this, the manager learns its plant productivity level. Then she decides whether the plant is operated or not and the amount of energy used and the number of workers hired. Figure 1 summarizes the timing of decisions at the plant level.

Notice that assuming that the number of plants cannot vary after the energy price is known implies that it is not possible to transform energy saving capital into productive capital in one period. After one period has elapsed, such a substitution is possible, but at a cost, as we will see later. We refer to this specificatio as the fi ed plants case, and later on we will discuss results of the model in the case of variable plants.

\subsubsection{Timing at the aggregate level}

At the beginning of a period $t$ the measure of plants that can operate at that period, $m_{t}$, has been already established. The energy price $p_{t}$ is observed and the idiosyncratic technology shocks at the plant level are realized. Plants decide whether to operate or not. This determines the fraction of plants operated during the period, which we denote as $n_{t}$. Plants that operate hire labor and use energy to produce output. Households consume and save. Then, the measure of plants that can operate next period, $m_{t+1}$, is determined. Figure 2 summarizes the timing of events at the aggregate level.

\begin{tabular}{lll}
$t$ & & \\
\hline$k_{t}$ & $p_{t}$ & $h\left(s_{t}, p_{t}\right)$ \\
$a_{t}$ & $s_{t}$ & \\
& & $e\left(s_{t}, p_{t}\right)$ \\
& & $d\left(s_{t}, p_{t}\right)$
\end{tabular}

Fig. 1. Timing of decisions at the plant level. 


$\begin{array}{lll}t & & t \\ m_{t} & p_{t} & n\left(s_{t}, p_{t}\right) \\ K_{t} & & \\ A_{t} & & \end{array}$

Fig. 2. Timing of events at the aggregate level.

\subsection{Capacity utilization and value added}

We now describe in more detail the determination of the measure of plants, $m_{t}$, the amount of productive and energy saving capital, $k_{t}$ and $a_{t}$, assigned to a plant; and the fraction of plants that operate, $n_{t}$. Consider fir t the problem faced by a plant's manager after $s_{t}$ has been observed, the price $p_{t}$ is known and $m_{t}, k_{t}$ and $a_{t}$ have already been determined. First of all, any plant operates either zero or $h_{0}$ hours, $h\left(s_{t}\right) \in\left\{0, h_{0}\right\}$. Recall that any amount of energy greater than $\gamma k_{t} / a_{t}$ has zero marginal productivity. Likewise, any number of workers beyond 1 does not produce any additional output. Therefore, the optimal plans for labor and energy use are

$$
d\left(s_{t}\right)=\left\{\begin{array}{ll}
1 & \text { if } h\left(s_{t}\right)=h_{0}, \\
0 & \text { otherwise }
\end{array} \quad e\left(s_{t}\right)= \begin{cases}\gamma k_{t} / a_{t} & \text { if } h\left(s_{t}\right)=h_{0}, \\
0 & \text { otherwise }\end{cases}\right.
$$

If the hourly wage is $w_{t}=w\left(K_{t}, A_{t}, p_{t}\right)$, where $K_{t}$ is the aggregate stock of productive capital, $A_{t}$ is the aggregate stock of energy saving capital, and $p_{t}$ is the energy price, it will cost $w_{t} h_{0}+p_{t} h_{0} \gamma k_{t} / a_{t}$ to operate the plant. It is profita le to operate the plant only if the output produced by the plant exceeds this cost. Hence, only plants with suff ciently large realized values of $s_{t}$ will be operated. That is,

$$
h\left(s_{t}\right)= \begin{cases}h_{0} & \text { if }\left(z+s_{t}\right) B k_{t}^{\theta} \geqslant w_{t}+p_{t} \gamma k_{t} / a_{t} \\ 0 & \text { otherwise. }\end{cases}
$$

Since all plants are ex-ante identical and $\theta<1$, all plants will be assigned the same amount of productive and energy saving capital: $k_{t}=K_{t} / m_{t}$, and $a_{t}=A_{t} / m_{t}$. Consequently, in equilibrium, there exists a threshold level, $s\left(K_{t}, A_{t}, p_{t}, m_{t}\right)$, below which the plant will not be operated. This implies that the equilibrium value for $s\left(K_{t}, A_{t}, p_{t}, m_{t}\right)$ is given by the solution to the following equation:

$$
\left[z+s\left(K_{t}, A_{t}, p_{t}, m_{t}\right)\right] B\left({\frac{K_{t}}{m_{t}}}^{\theta}=w_{t}+p_{t} \gamma \frac{K_{t}}{A_{t}} .\right.
$$

Since $s_{t}$ is uniformly distributed, the fraction of plants that will operate is

$$
n_{t} \equiv n\left(K_{t}, A_{t}, p_{t}, m_{t}\right)=\int_{s\left(K_{t}, A_{t}, p_{t}, m_{t}\right)}^{\sigma} \frac{1}{2 \sigma} \mathrm{d} s=\frac{\sigma-s\left(K_{t}, A_{t}, p_{t}, m_{t}\right)}{2 \sigma} .
$$

Therefore, we can rewrite Eq. (7) as a function of the fraction of plants that are operated:

$$
\left[z+\sigma-2 \sigma n_{t}\right] B\left({\frac{K_{t}}{m_{t}}}^{\theta}=w_{t}+p_{t} \gamma \frac{K_{t}}{A_{t}},\right.
$$


which, in turn, determines the equilibrium value of $n_{t}$ given $m_{t}, w_{t}, p_{t}, K_{t}$ and $A_{t}$. Thus, aggregate gross output across plants is

$$
\begin{aligned}
G O_{t} & =\int_{s\left(K_{t}, A_{t}, p_{t}\right)}^{\sigma}\left(z+s_{t}\right) B\left({\frac{K_{t}}{m_{t}}}^{\theta} h\left(s_{t}\right) m_{t} \frac{\mathrm{d} s}{2 \sigma}\right. \\
& =\left(z+\sigma\left(1-n_{t}\right)\right) n_{t} B\left({\frac{K_{t}}{m_{t}}}^{\theta} m_{t} h_{0} .\right.
\end{aligned}
$$

Aggregate use of energy across plants is

$$
E_{t}=\gamma \frac{K_{t}}{A_{t}} m_{t} n_{t} h_{0}
$$

Therefore, value added is

$$
Y_{t}=\left(z+\sigma\left(1-n_{t}\right)\right) n_{t} B K_{t}^{\theta} m_{t}^{1-\theta} h_{0}-p_{t} \gamma \frac{K_{t}}{A_{t}} m_{t} n_{t} h_{0} .
$$

\subsection{The social planner's problem}

The economy is populated by a large number of inf nitely lived households and its total measure is one. Households are ex-ante identical and seek to maximize expected discounted lifetime utility

$$
E_{0} \sum_{t=0}^{\infty} \beta^{t}\left(\log c_{t}+\alpha \log l_{t}\right), \quad \beta \in(0,1), \alpha>0,
$$

where $c_{t}$ denotes consumption at date $t$ and $l_{t}$ denotes leisure. Households are endowed with one unit of time that can be allocated to either work, $h_{t}$, or leisure, so $l_{t}=1-h_{t}$. Following Rogerson (1988) and Hansen (1985), labor is assumed to be indivisible; in a given period households can work either a shift of length $h_{0}$, or not at all, where $h_{0}$ is exogenously given.

Feasibility at each period $t$ is

$$
\begin{aligned}
c_{t} & +X_{k t}+X_{a t}\left[1+g\left(\frac{X_{a t}}{A_{t}}\right.\right. \\
& \leqslant\left(z+\sigma\left(1-n_{t}\right)\right) n_{t} B K_{t}^{\theta} m_{t}^{1-\theta} h_{0}-p_{t} \gamma \frac{K_{t}}{A_{t}} m_{t} n_{t} h_{0} .
\end{aligned}
$$

Capital of each type held at the beginning of the subsequent period is

$$
\begin{aligned}
& K_{t+1}=(1-\delta) K_{t}+X_{k t}, \\
& A_{t+1}=(1-\delta) A_{t}+X_{a t},
\end{aligned}
$$

where $X_{k t}, X_{a t}$ denote investment in productive and energy saving capital, respectively, undertaken in period $t$. Investing one unit of resources in energy saving capital costs $1+g\left(X_{a t} / A_{t}\right)$ units of resources. That is, there are adjustment costs associated to changes in the stock of installed energy saving capital. There are two ideas that we want to capture 
introducing this specif cation of adjustment costs: changing the level of energy eff ciency in the economy (augmenting the level of energy saving capital) and changing the use of capital (reallocating capital from its productive use to be utilized as energy saving capital) are costly. Our strategy here is not particularly concerned with the role of aggregate adjustment costs as determinants of investment demand; rather, it tries to stress the different nature of the two uses of capital in our model.

The adjustment cost function $g(\cdot)$ is assumed to be homogeneous of degree zero in $X_{a}$ and $A$. It satisfie that $g(\delta)=0$ and $g^{\prime}(\delta)=0$, so that the steady-state capital stock is not affected by the introduction of adjustment costs. Moreover, it implies that the relative price of both types of capital is one in the steady state. We will come back to this implication in Section 3.

Since labor is indivisible in this economy, we follow Rogerson (1988) and Hansen (1985) by allowing agents to trade employment lotteries. Given a wage rate, households choose a probability of working $h_{0}$ hours, denoted $\pi_{t}$, in order to maximize expected utility. We assume that households have access to a market for unemployment insurance. Since preferences are additively separable in consumption and leisure households will insure themselves so that their consumption levels are independent of whether or not they work. Given this, in equilibrium, aggregate units of labor are equal to the number of workers per plant times the fraction of operating plants times the length of the workweek:

$$
\pi_{t} h_{0}=m_{t} n_{t} h_{0} .
$$

We can def ne a social planner's problem recursively in two steps. First, the planner chooses the number of plants that maximizes the expected future value of discounted utility before the energy price is realized, conditional on the information set $\left\{K_{t}, A_{t}, p_{t-1}\right\}$. Second, the planner decides the levels of consumption, investment in both types of capital, and the fraction of plants that will operate once the energy price shock is realized. Solving backwards, we frst take as given the number of prospective plants. Given the number of plants, the problem solved is

$$
W(K, A, p, m)=\max _{c, X_{k}, X_{a}, n \in[0,1]}\left\{\log (c)+\alpha \log \left(1-h_{0}\right) m n+\beta V\left(K^{\prime}, A^{\prime}, p\right)\right\}
$$

subject to

$$
\begin{aligned}
& c+X_{k}+X_{a}\left[1+g\left(\frac{X_{a}}{A} \leqslant(z+\sigma(1-n)) n B K^{\theta} m^{1-\theta} h_{0}-p \gamma \frac{K}{A} m n h_{0},\right.\right. \\
& K^{\prime}=X_{k}+(1-\delta) K, \\
& A^{\prime}=X_{a}+(1-\delta) A,
\end{aligned}
$$

where

$$
V\left(K^{\prime}, A^{\prime}, p\right)=\max _{m^{\prime}} E\left\{W\left(K^{\prime}, A^{\prime}, p^{\prime}, m^{\prime}\right) \mid p\right\} .
$$

\subsection{Value added, heterogeneity of plants and capacity utilization}

In this subsection we want to discuss some modelling choices that we have made. It is easy to show that per capita value added can also be written in a more conventional way as 
a function of aggregate capital and labor. To do that we would need to solve the following problem:

$$
F\left(K_{t}, A_{t}, p_{t}, H_{t}\right)=\max _{n_{t}}\left\{\left(z+\sigma\left(1-n_{t}\right)\right) n_{t} B K_{t}^{\theta} m_{t}^{1-\theta} h_{0}-p_{t} \gamma \frac{K_{t}}{A_{t}} m_{t} n_{t} h_{0}\right\}
$$

$$
\text { subject to } H_{t}=h_{0} m_{t} n_{t} \text {, }
$$

whose solution is given by

$$
\begin{aligned}
& F\left(K_{t}, A_{t}, p_{t}, H_{t}\right)=\psi_{t} B K_{t}^{\theta} H_{t}^{1-\theta}-p_{t} \gamma \frac{K_{t}}{A_{t}} H_{t}, \\
& \psi_{t}=\left(z+\sigma\left(1-n_{t}\right)\right)\left(n_{t} h_{0}\right)^{\theta} .
\end{aligned}
$$

Equation (21) shows that value added displays constant returns to scale in the three primary factors of production. Notice that total energy use in this notation is $E_{t}=\gamma\left(K_{t} / A_{t}\right) H_{t}$. Two things are worth noting: frst, factor shares are not constant in this environment, and second, total factor productivity def ned as the Solow's residual depends on the fraction of operated plants. We want to discuss two issues: modelling production at the plant level, and heterogeneous plants.

First, it could be argued that the assumption that production is carried out in plants is not necessary and that we could have assumed the following technology:

$$
\begin{aligned}
& Y_{t}=B\left(K_{t}^{1-2 \phi} Z_{E t}^{\phi} A_{t}^{\phi}\right)^{v} H_{t}^{1-v}-p_{t} Z_{E t}, \\
& Z_{E t}=\min \left\{E_{t}, \gamma \frac{K_{t}}{A_{t}} H_{t}\right\} .
\end{aligned}
$$

Optimally, $Z_{E t}=\gamma\left(K_{t} / A_{t}\right) H_{t}$ and value added could be written as

$$
Y_{t}=B \gamma^{\phi v} K_{t}^{v(1-\phi)} H_{t}^{1-v+\phi v}-p_{t} \gamma \frac{K_{t}}{A_{t}} H_{t},
$$

which only differs from (21) in the fact that it is not possible to talk about capacity utilization. We think that a fi ed requirement as the one shown in (24) is very diff cult to defend at the macroeconomic level. This is why we model technology at the plant level.

Second, the assumption of differences in productivity across plants could be thought of as not necessary. We could have assumed that all plants had an idiosyncratic shock equal to the mean of $s_{t}$ and then we would not need to address the issue of capacity utilization. This modelling choice has a problem. In the case in which variable costs, i.e., labor and energy costs, were equal to aggregate gross production energy and labor demands would be indeterminate at the aggregate level. This problem does not arise when we assume ex-post productivity differences across plants.

\section{Calibration}

First of all, we brief y discuss the data we use. We construct series for the energy price and energy use as well as economic aggregates for the period 1960-1999. Since we assume that all energy is imported in our model economy, we need to construct measures 
of value added, investment and capital stock excluding, respectively, output, investment, and capital of energy producing sectors. To obtain an aggregate series on energy use for the US economy, we construct a constant-price measure of the use of electricity, petroleum, coal, and natural gas. Correspondingly, our aggregate energy price is the ratio of energy use measured in current prices to energy use measured in constant prices. A full explanation of the sources and methods used in our data construction is given in Appendix A.

We calibrate our model economy so that its non-stochastic steady state is consistent with a list of long-run properties for the US economy implied by our reference data set. These include the fact that the average capital-value added ratio is 2.7873 , investment as a share of output is 0.2325 , the share of capital in value added is 0.4 , the share of energy expenditures in value added is 0.0463 , and the average fraction of total substitutable time that households spend working in the market is 0.31 .

The time period is a year. In our model economy GDP, or value added, is gross output net of energy expenditures:

$$
Y=(z+\sigma(1-n)) n B K^{\theta} m^{1-\theta} h_{0}-p \gamma \frac{K}{A} m n h_{0} .
$$

We take the view that energy saving capital is tangible capital. Moreover, since adjustment costs in the steady state are zero its relative price is one. Further, we assume that productive capital and energy saving capital depreciate at the same rate. This implies that the net return of both types of capital is the same. Therefore, the capital-energy ratio implies that $\theta$, the share of productive capital in gross output should be equal to 0.3823 for the share of capital in value added to be equal to 0.4 . The chosen investment rate together with the capital-value added ratio imply a depreciation rate for capital equal to 0.0834 . The interest rate net of depreciation, implied by the capital share and the capital-value added ratio is 6.01 percent. This, in its turn, implies a discount factor equal to 0.9433 .

Since the return of both types of capital is equal in equilibrium, this implies that the ratio $K / A$ is 7.6485 . Notice that

$$
p E=p \gamma \frac{K}{A} n m h_{0} .
$$

Thus, we set $\gamma$ so that energy expenditures are 4.63 percent of value added. Next, we obtain a value for energy saving capital. This value makes consistent a net interest rate of 6.01 percent and a value of energy expenditure of 4.63 percent. We $f$ nd that the value of energy saving capital is roughly 33 percent of GDP. This value may seem large. Trying to identify the industries producing what Doms and Dunne (1993) call advanced manufacturing technologies (AMTs), we have selected a list of some industries which we think produce capital goods that directly or indirectly contribute to energy-saving at the plant level. This selection (in Business Expenses, Manufacturing, Table 31: Value of Shipments and Selected Operating Costs, 1997 Economic Census) includes, for instance, hardware manufacturing; industrial valve mnf; semiconductor machinery mnf; speed changer, industrial high speed drive and gear mnf; f ber optic cable mnf; industrial process control instrument mnf; and so on. Taking the value of shipments of these industries as an indicator for the value of aggregate AMT purchases, we fnd that the GDP share of AMT investment is 0.04307 , which implies a value for technology capital $(A)$ equal to 51.62 
percent of GDP. We think our steady-state value reported above is reasonable in light of this evidence.

First-order conditions from the planner's problem particularized in the steady state determine that

$$
n=\frac{\theta(z+\sigma)}{\sigma(1+\theta)}
$$

Following Cooley et al. (1995) and Bresnahan and Ramey (1993), we def ne capacity utilization rate as level of output divided by the level of output that would be obtained if all plants produce at a given period. Thus, the fraction of plants operated in equilibrium, $n$, and consequently $\sigma$, are chosen so that capacity utilization rate is 82.08 percent:

$$
\frac{(z+\sigma(1-n)) n B K^{\theta} m^{1-\theta} h_{0}-p \gamma \frac{K}{A} m n h_{0}}{z B K^{\theta} m^{1-\theta} h_{0}-p \gamma \frac{K}{A} m h_{0}}=0.82 .
$$

Equations (28) and (29) determine the value of $n$ and $\sigma$. The value of $m$ is set so that hours worked in the model, $m n h_{0}$, are equal to 0.31 . The parameter $\alpha$ makes consistent these values with the fact that the planner chooses the optimal number of plants, $m$. The scale parameter $B$ is chosen so that value added is normalized to 1 .

The adjustment cost function $g(\cdot)$ is assumed to be homogeneous of degree zero in $X_{a}$ and $A$. We assume that $g(\delta)=0$ and $g^{\prime}(\delta)=0$, so that the steady-state capital stock is not affected by the introduction of adjustment costs. A third parameter that must be specif ed is the elasticity of the marginal adjustment cost function, which governs the response of energy saving capital to movements in Tobin's $q$ (the ratio of the shadow price of installing new energy saving capital over the price of consumption). We let $b$ denote this elasticity.

Previous empirical work is not particularly helpful to set $b$ in our case. Alternatively, targeting any second moments properties of the model to calibrate this parameter would require us to have a measure of technology shocks, but this is not trivial. Instead, our strategy here combines part of the $\mathrm{f}$ ndings in Cooley et al. (1995) with some of our results. On the one hand, Cooley et al. (1995) show that a fxed-plants model exhibits output f uctuations due to technology shocks that are roughly 80 percent of those of an otherwise identical variable-plants economy. On the other hand, we f nd that output fuctuations due to energy price shocks in our variable-plants economy are roughly 60 percent of those in actual data. Consequently, we set $b$ to leave technology shocks in our $\mathrm{f}$ xed-plants economy the room to account for 32 percent of the volatility of output. This is obtained when the value of the elasticity of marginal adjustment costs is $7 .{ }^{7}$ With this selection, simulated values of Tobin's $q$ range from 0.89 to 1.2 , except for the 1981 oil shock (1.26). These values seem quite reasonable according to empirical estimates (the highest values of $q$ estimated in the investment literature are barely above 2 ). In any case, we present results for a wide range of the adjustment-cost elasticity in Section 4.1.

\footnotetext{
7 Indeed, the volatilities of (HP, $\lambda=100)$ detrended GDP and value added in the model $(b=7)$ are $\sigma_{y} D=0.0219$ and $\sigma_{y} M=0.0149$, respectively.
} 
Table 1

Values of the parameters

\begin{tabular}{ccccccc}
\hline$\beta$ & $\alpha$ & $\sigma$ & $\theta$ & $\gamma$ & $\delta$ & $B$ \\
\hline 0.9433 & 2.0047 & 0.8121 & 0.3823 & 0.0219 & 0.0834 & 2.0288 \\
\hline
\end{tabular}

Table 2

Steady state

\begin{tabular}{cccccc}
\hline$Y$ & $K$ & $A$ & $m$ & $n$ & $E$ \\
\hline 1.0000 & 2.4650 & 0.3223 & 1.3219 & 0.6171 & 0.0518 \\
\hline
\end{tabular}

Finally, following Finn (1996), Kim and Loungani (1992) and Atkeson and Kehoe (1999), we estimate an $\operatorname{ARMA}(1,1)$ process for the international price of energy parameterized by

$$
\log p_{t+1}=(1-\rho) \log \bar{p}+\rho \log p_{t}+\phi \epsilon_{t}+\epsilon_{t+1}
$$

where $\epsilon_{t} \sim N\left(0, \sigma_{\epsilon}^{2}\right)$ and $\bar{p}$ is the average energy price in the data. Using annual energy price data from the 1960-1999 period, $\rho=0.8923, \bar{p}=0.8926, \phi=0.3427$ and $\sigma_{\epsilon}=$ 0.0866 .

The values obtained for the rest of the parameters are shown in Table 1, and the steadystate values of some aggregate variables are shown in Table 2.

\section{Results}

In this section we report our finding . We present two types of results in accordance with the selected evidence we mentioned energy economists have identif ed. First, we discuss the results concerning the time series predictions of the model. To assess the ability of our model to account for the time-series data on energy expenditure and energy use, we simulate it, feeding in the data on the energy price to obtain predictions for the time paths of energy use, energy expenditure, capital and output. Secondly, we evaluate the ability of our model to be consistent with the observation that energy use seems responsive to permanent differences in energy prices. To this purpose we consider the effect on energy use and output of an energy tax that leads to a doubling of energy prices in the model.

\subsection{Time series responses to energy price changes}

The main feature of energy aggregates is that energy use is not very responsive to energy price changes whereas energy expenditure varies very much. Atkeson and Kehoe's (1999) analysis of energy intensity choice in a model with differentiated putty-clay capital goods offers a fairly good explanation of this feature of actual time series. The main message of their study is that short-run complementarity between capital and energy is needed to account for the time series behavior of energy use and energy expenditure. The problem is then that their model economy falls short of accounting for the substitutability of energy for capital observed in the data. More precisely, the capital-to-energy ratio in their model 
lags that in the data and fuctuates less than in the data. However, this is not the case when the technology is putty-putty instead. This leads us to conclude that it is not clear whether a putty-clay model captures satisfactorily the channels through which energy is substituted for capital.

We show next that the capital reallocation friction our model implements does the job of simultaneously explaining

(i) the aggregate response of energy variables to energy price changes and

(ii) the magnitude and timing of specif c investments intended to absorb energy price shocks.

\subsubsection{The behavior of energy use and energy expenditure}

In Fig. 3, we compare the time series for the logarithm of the ratio of energy expenditure to nominal GDP and the ratio of energy use to real GDP for the model and the data for the period 1960-1999. In addition, we have calibrated Atkeson and Kehoe's (1999) puttyclay model according to our data to compare the results of our model and theirs. We f rst describe brief $y$ their model and then turn to present the results.

Atkeson and Kehoe (1999) depart from the neoclassical framework and analyze energy intensity choice in a putty-clay model in which a large variety of types of capital goods are combined with energy in different $f$ xed proportions. In their setup, a more eff cient

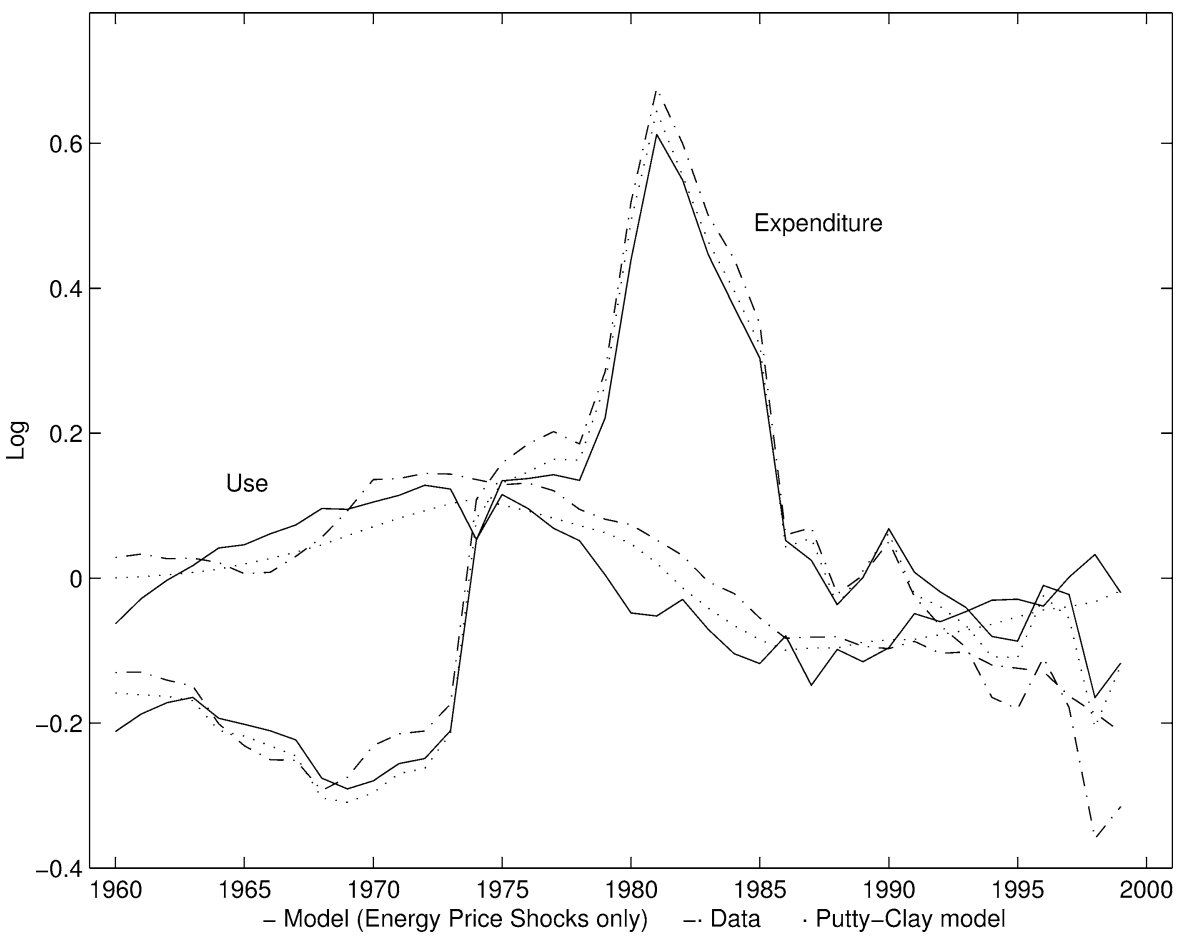

Fig. 3. Energy use and energy expenditure. 
capital good is that which needs fewer units of energy per unit of capital. Using a more eff cient type has a cost, however; gross production per unit of capital is lower the more eff cient the type is. The f nal good is produced with capital services and labor according to a Cobb-Douglas technology. Atkeson and Kehoe (1999) assume that households do not value leisure. To solve their model we proceed as the authors do: we assume that capital is never left idle. Thus, in equilibrium all existing types are utilized although investment only takes place in the newest type created. Old, ineff cient types are used in production but are left to depreciate.

As we can see, energy use does not fuctuate much and it is energy expenditure which absorbs all the price change. As we have already mentioned, both models behave in accordance to the evidence along this dimension.

\subsubsection{The behavior of the capital to energy ratio}

Figure 4 shows the evolution of the logarithm of the capital-energy ratio predicted by ours and Atkeson and Kehoe's (1999) putty-clay model and compares them to the data. In their case, the capital-energy ratio moves too slowly. The reason for this behavior is that old ineff cient types of capital goods are always utilized, which does not allow the aggregate capital-energy ratio to move as fast and vary as much as in the data. Our model, on the contrary, has a greater ability to substitute energy for capital. The behavior of the

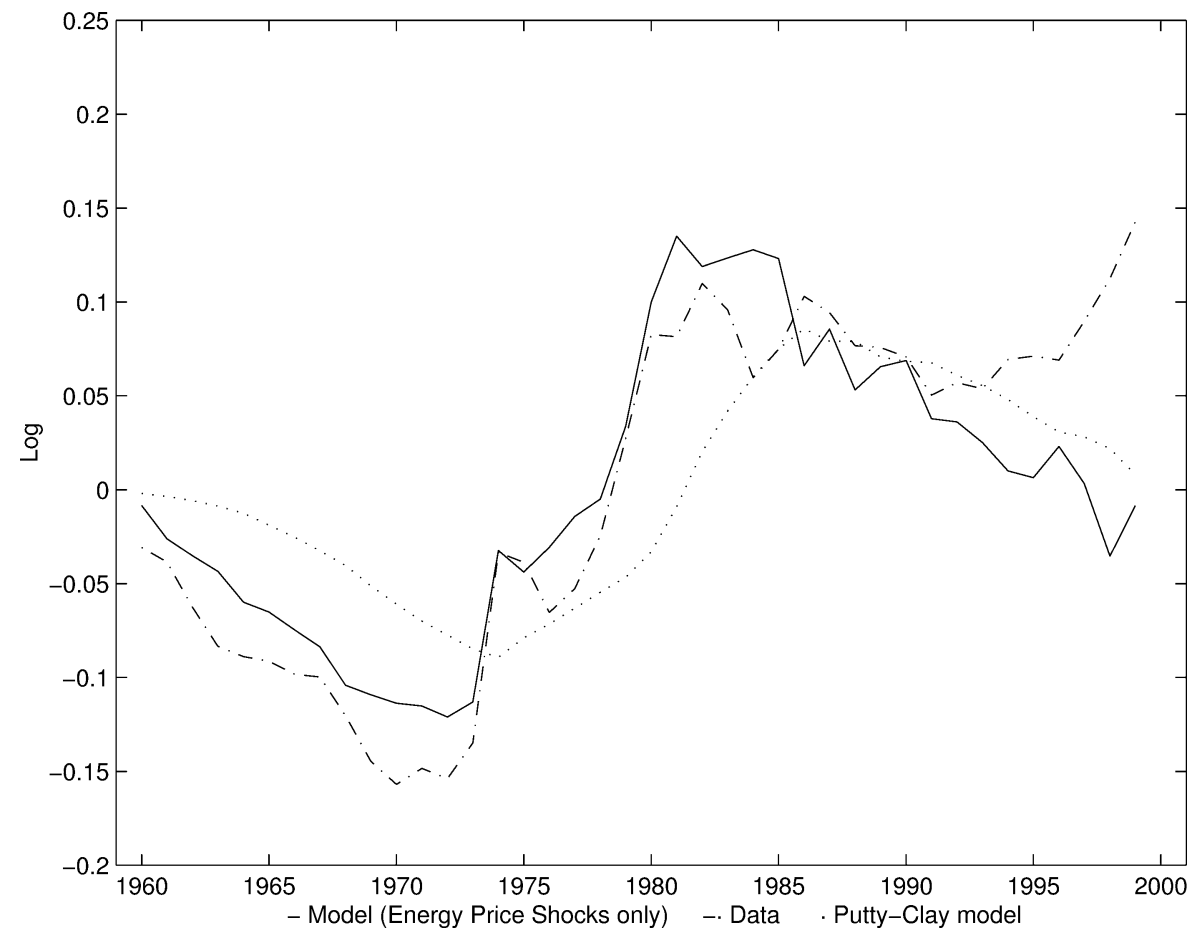

Fig. 4. Evolution of the capital-energy ratio. 

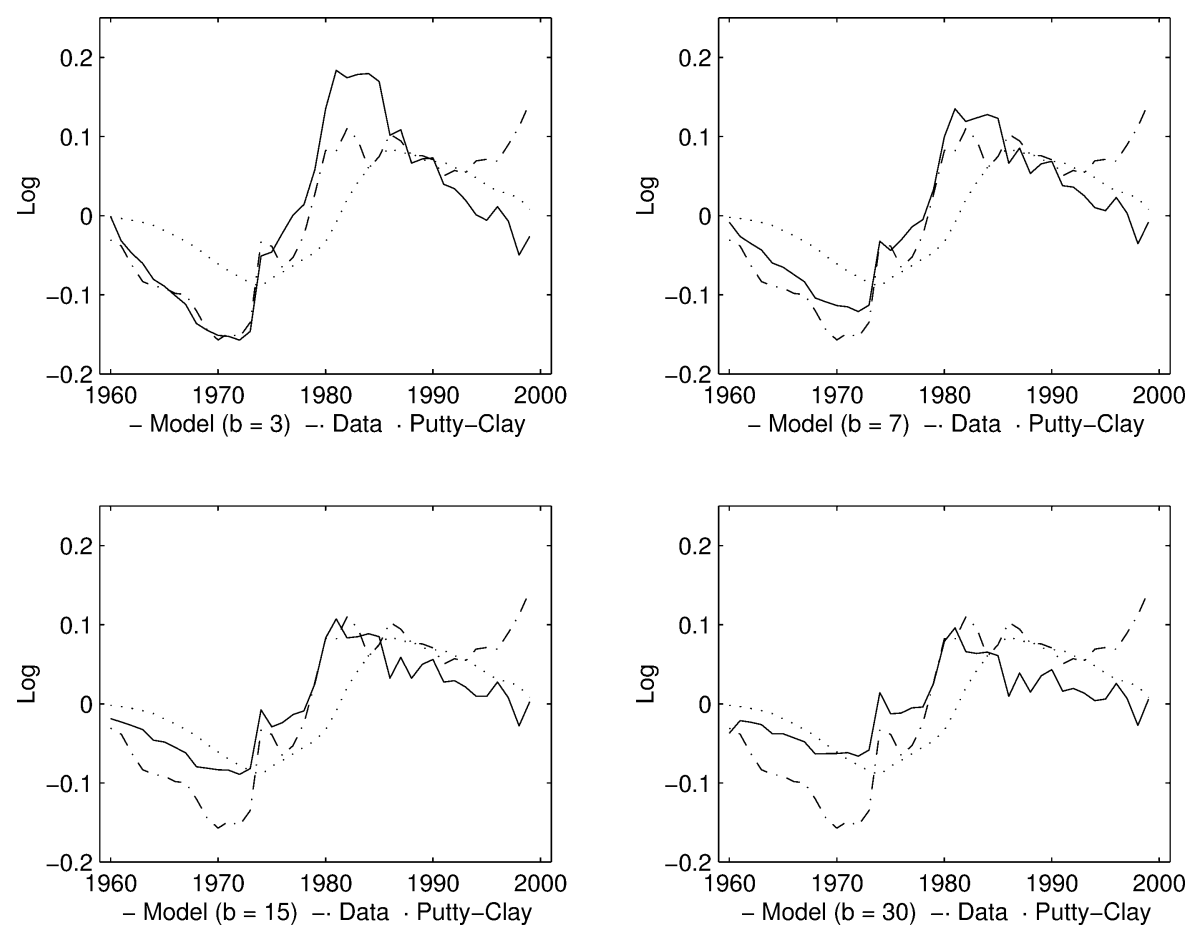

Fig. 5. Capital-energy ratio for different values of $b$.

model along this dimension gives us an idea of the degree of complementarity between capital and energy implied respectively by a putty-clay framework and our framework.

Notice that, in our model, productive capital and energy saving capital have different relative prices out of the steady state. Therefore, to add up units of productive and energy saving capital in our simulated data we use the simulated values of Tobin's $q$. Given the realized values of $q$ documented above (range from 0.9 to 1.2 ) the results are robust to this requirement of consistent measurement.

Figure 5 highlights the different ability of our framework and Atkeson and Kehoe's (1999) putty-clay model to substitute energy for capital. In this figur we show the results of the model for different values of the elasticity of the adjustment cost, $b$. As we have explained in the calibration Section we have set the value of $b$ equal to 7 so that energy price changes account for 68 percent of the observed volatility of annual GDP during the period 1960-1999. The higher is the response of energy saving capital to changes in the relative price of this type of investment (the lower is $b$, cf. $b=3$ ) the predictions of our model are close to a putty-putty model in which capital and energy are imperfect substitutes. On the contrary, the higher is $b$, the greater the importance of the adjustment costs, the closer the predictions of our model to those of Atkeson and Kehoe's (1999).

Thus, Fig. 5 reveals that the degree of complementarity between capital and energy in Atkeson-Kehoe's framework is much higher than that implied by the evidence. This suggests that in the Atkeson-Kehoe's framework in the short run the economy cannot 


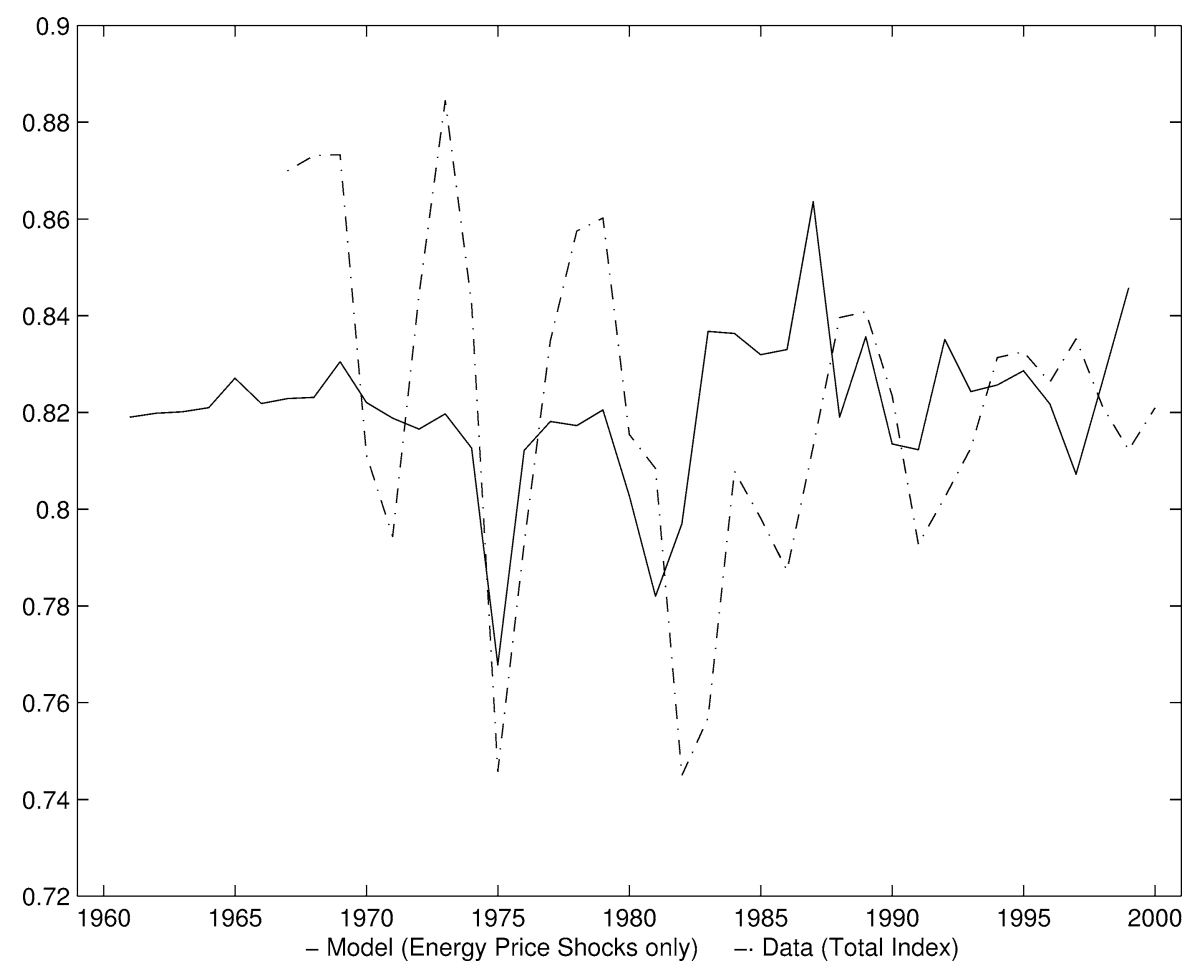

Fig. 6. Total capacity utilization rate.

react to bad price shocks and, hence, their negative effects will be more persistent over time. We will turn to this point again in Section 4.2 when we discuss the medium and long-run properties of both model economies.

\subsubsection{Predictions on capacity utilization}

Figure 6 shows the predicted evolution of the total capacity utilization rate and compares it to the corresponding series of total capacity utilization for the US economy. As we can see, our model does well at capturing the drop in the capacity utilization rate during the period of major oil price shocks, 1975-1981, and offers worse predictions for the later period 1981-1999. We need to keep in mind that we only have considered energy price shocks and that we have abstracted away from aggregate technology shocks. Consequently, energy price shocks are an important source of variability in capacity utilization during the major oil crisis periods, which is consistent with the micro evidence provided in Bresnahan and Ramey (1993).

\subsubsection{Discussion of the results}

The intuition about the evolution of our simulated data after an energy price increase is the following: since in the short run capital and energy are complements, given the capital installed at the plant, the energy bill is also given and independent of the productivity of 
the plant. Thus, only plants with high productivity operate. Therefore, capacity utilization rate immediately falls. This is followed by a reduction in the number of plants established next period. The reason for this fall in the number of plants is that persistence in the energy price makes the managers of the prospective plants to expect a high energy price. The reduction in the energy bill through this channel, however, is very limited. The substitution of productive capital for energy saving capital is costly and takes time, as well as it is investing in new energy saving capital. Therefore, energy expenditure fluctuate very much, whereas energy use does not.

To understand the role of variable capacity utilization and capital adjustment costs we simulate a version of our model in which investment in energy saving capital is not subjected to adjustment costs and in which the number of plants is allowed to vary after the energy price is known.

The existence of adjustment costs is crucial for energy use being inelastic in time-series data. In absence of this cost, our model predicts that energy use varies too much, whereas energy expenditure does not. Accordingly, the capital to energy ratio f uctuates too much compared to the data (see Figs. 7 and 8). The reason for this behavior is that, after a change in the energy price, productive capital can be swiftly reallocated and used as energy saving capital at no cost, and vice versa, even keeping aggregate investment constant. Thus, what is key for the model to reproduce the time series evidence is that reallocation of capital is costly. When the number of plants can vary after the energy price is known the fraction

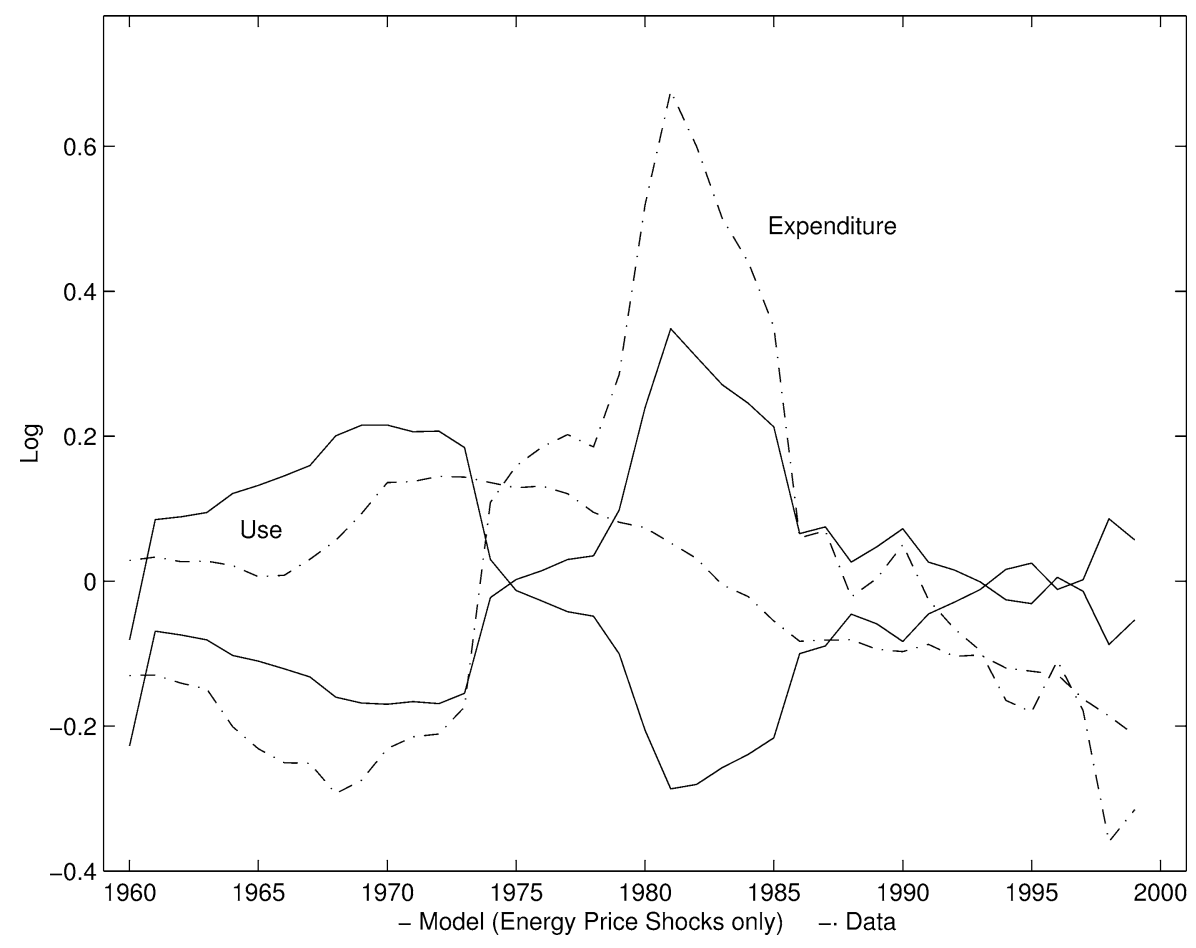

Fig. 7. Energy use and expenditure. No adjustment costs and variable plants. 


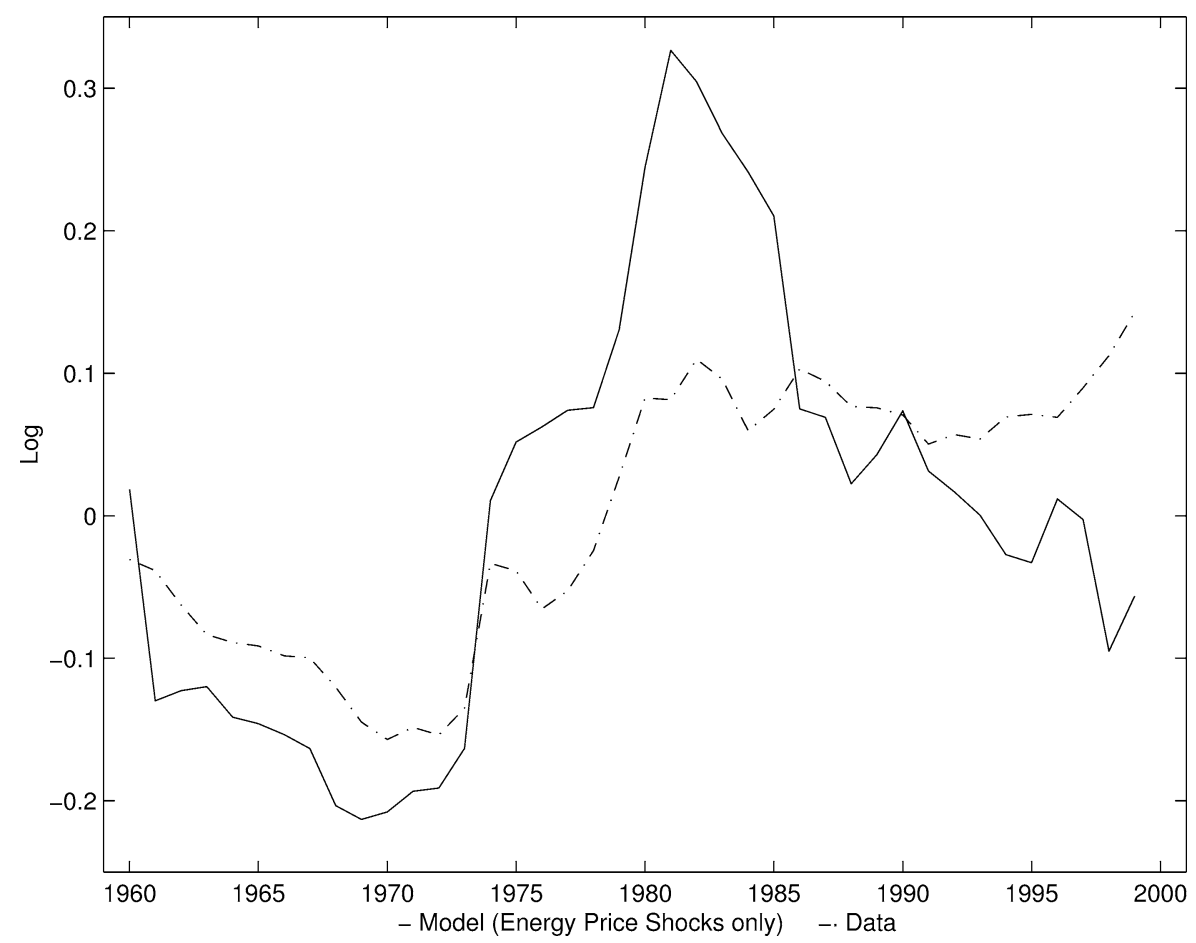

Fig. 8. Capital-energy ratio. No adjustment costs and variable plants.

of operated plants is invariant with respect to the energy price and, therefore, capacity utilization is not affected by changes in the price. Rather, changes in the number of plants allow gross production per worker to vary with the energy price and, therefore, the fraction of operated plants does not change. Consequently, capacity utilization does not vary with changes in the energy price (see Fig. 9). Basically, our model behaves as the Pindyck and Rotemberg (1983) putty-putty model with physical capital subject to adjustment costs. Energy use is very responsive, whereas energy expenditure is not.

\subsection{Cross-section results}

We mentioned in the introduction that in cross-section data across countries energy use is very responsive to international differences in energy prices. That is, energy use is not elastic in the short run but it is so in the long run. This implies that in the long run, energy and capital are substitutes and that countries with higher prices use a higher capitalenergy ratio. Therefore, cross country differences in per capita output due to energy prices differences should not be large. We test the performance of our model in this dimension conducting the following experiment: we consider the effect on energy use and output of an energy tax that leads to a doubling of energy prices in this model. We assume that the revenue collected is spent on public goods that affect neither the steady-state real returns 


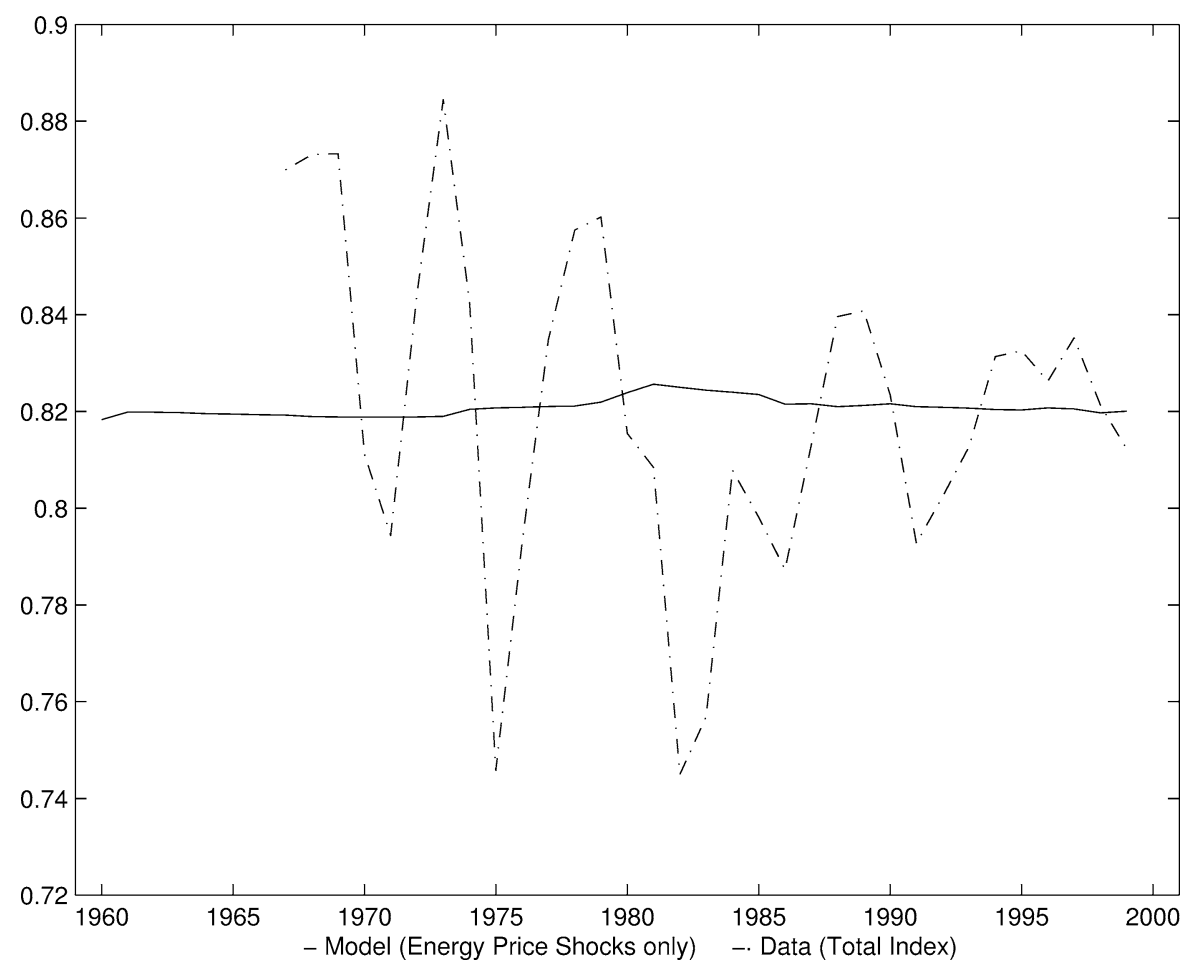

Fig. 9. Total capacity utilization rate. No adjustment costs and variable plants.

nor the steady-state marginal product of capital. Figure 10 shows the transition of GDP for each economy from the initial to the fina steady state. ${ }^{8}$

In our model a doubling of the energy price leads to a 3.94 percent drop in the capital stock. Energy use, as percent of GDP decreases by 30 percent. The fall in aggregate consumption and investment is 5.71 percent. Substracting the value of taxes raised to this value, since we assume they f nance a public good, the fall in long-run GDP is 2.60 percent. The revenue raised from the tax in the long run is 3.30 percent of long-run GDP. These numbers are comparable to those estimated by Goulder (1992, 1993, 1995), and Jorgenson and Wilcoxen (1993). The fall in long-run GDP in the putty-clay framework is 3 percent. We should keep in mind that labor supply is exogenously given in their model, whereas in ours is not. Consequently, if labor were endogenous the predicted fall in output would be higher in their model. Figure 10 illustrates the differences between both frameworks. In our model, the short-run fall in GDP is greater reflecti $g$ the reallocation of capital from its productive to its energy saving use, but also the recovery is faster and the long-run impact of taxes on long-run GDP is lower.

8 To compute this deterministic transition we use a version of the LBJ algorithm as implemented and extended in Dynare (see Juillard, 1997). 


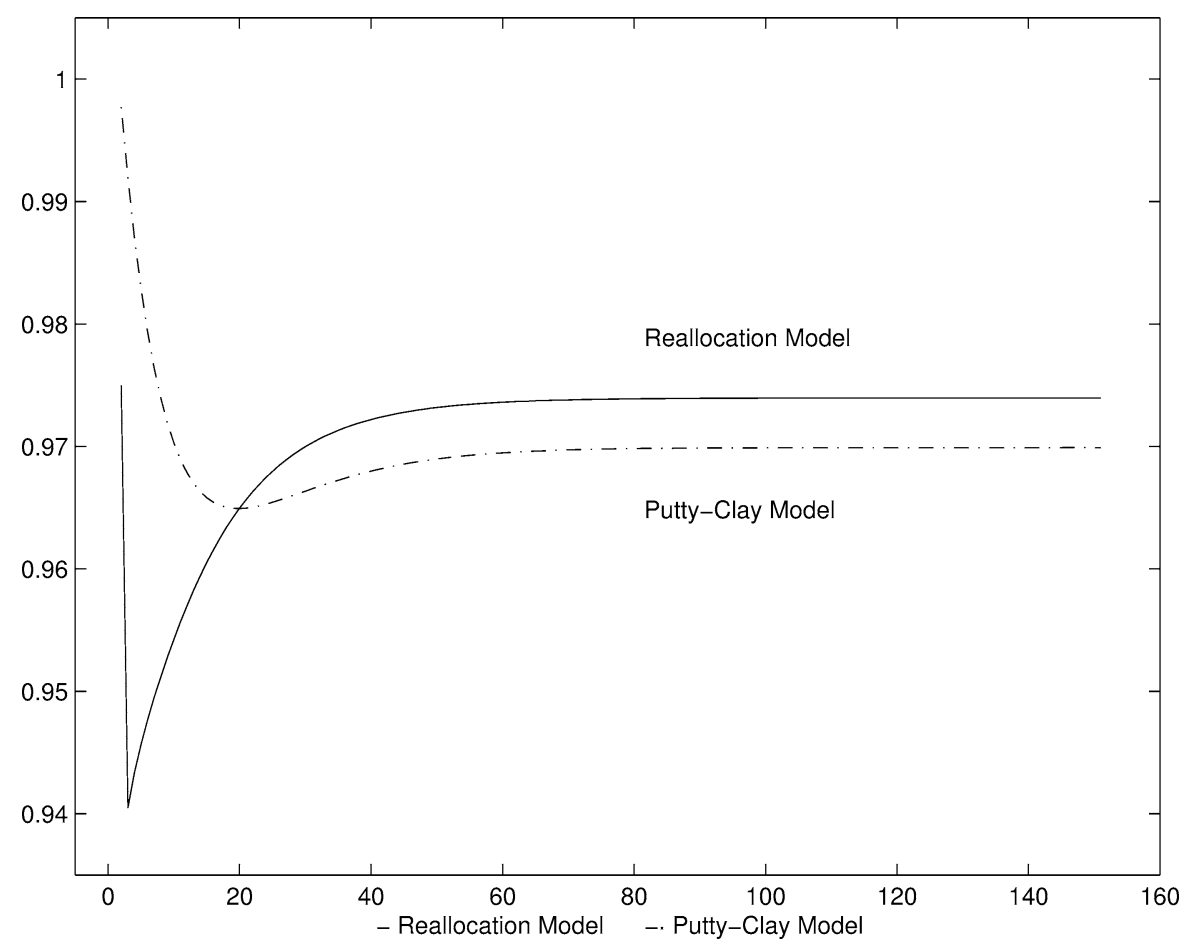

Fig. 10. Evolution of GDP after the tax.

\section{Final comments}

In this paper we have built a version of the neoclassical growth model augmented with a second type of physical capital that acts purely as an energy saving device. We interpret this capital good as induced energy-saving innovation and we will call it energy saving capital. The model is able to justify two salient features of the data: First, that in time series, energy use is not very responsive to energy price changes, whereas energy expenditure f uctuates much. Secondly, in cross-section data for different countries big international differences in energy prices do not lead to big differences in per capita output. These f ndings point to a very specif $\mathrm{c}$ and potentially important friction that inf uences the aggregate response to energy price changes, namely, costly capital reallocation. Additionally, to any capital use corresponds a given energy requirement and production takes place at the plant level. The standard features of the neoclassical growth model are otherwise preserved.

We have also compared the predictions of our model with those obtained by Atkeson and Kehoe (1999). Both models offer similar predictions about the time series behavior of energy use and energy expenditure. They differ notably in their ability to substitute capital for energy. Specif cally, the evolution of the capital-energy ratio in our model resembles very closely that of the data whereas it does not in Atkeson and Kehoe's case. This would have important consequences if, for instance, we want to study the welfare effects of an energy price increase or the business cycle properties of the main aggregates. It also 
suggests that bad energy shocks will have more persistent negative effects in a putty-clay model than in our framework.

Consequently, we consider our model specif cation a promising tool for analyzing the importance of energy price shocks and the channels through which they drive economic fuctuations.

\section{Acknowledgments}

We thank Tim Kehoe, Omar Licandro, and José Victor Ríos-Rull for helpful comments. We also thank Andrew Atkeson and Patrick Kehoe for kindly giving us access to the data set they use in their article. We are grateful to the editor and two anonymous referees for their very helpful comments and suggestions. Díaz thanks the Spanish Ministry of Education, DGCYT, project BEC2001-1653, for f nancial support. Puch thanks the DGCYT, projects PB98-0831, and SEC 2000-0269 and the Fundación Ramón Areces. Guilló thanks the DGCYT, project BEC2001-0535. This work appeared as Working Paper of the Instituto Valenciano of Investigaciones Económicas, AD-2000-14. We thank the IVIE for its support.

\section{Appendix A. Data construction}

In this appendix we document the construction of the data series we use in the empirical part of the paper. We obtain data from two sources: Annual Energy Review (2000) and National Income and Product Accounts. The data we use can be accessed in the addresses: http://www.eia.doe.gov and http://www.bea.doc.gov. From now on we will refer to each source as AER and NIPA, respectively. We follow Atkeson and Kehoe's (1999) procedure to construct the data series for the period studied, 1960-1999. Our data set is available upon request.

\section{A.1. Energy price, use, and expenditures series}

The energy data covers the energy consumption of end users. We consider four forms of energy: coal, petroleum, natural gas and electricity. AER (Table 2.1) gives data on total energy consumption by end users measured in British termal units (BTUs) disaggregated into the four forms of energy considered. We denote these data on energy use for each type of energy by $Q_{i t}$, where the index $i$ denotes the form of energy.

This measure $Q_{i t}$ is already net of energy use of the electricity sector. There are no corresponding data on the energy use by type of the other three energy-producing sectors. There are no data on energy consumption by the natural gas sector. We assume that the energy consumed by this sector is zero. We assume that the BTUs consumed by the coal and petroleum sectors are divided among the four forms of energy according to the averages shares of the industrial sector. These shares are constructed from the data contained in Table 2.2 therein. 
We construct a constant-price measure of energy use. We choose the base year to be 1987 and def ne energy use to be $E_{t}=\sum_{i} Q_{i t} P_{i 0}$, where $P_{i 0}$ is the price in dollars per BTUs of energy type in 1987 from AER. For coal, natural gas and petroleum we use the production price series (AER, Table 3.1). For electricity, we use the retail price of electricity sold by electric utilities (see AER, Table 8.13). All prices are real prices in dollars of 1996. In Table 8.13 the price for electricity is in cents per kilowatt-hour. We use AER Table 13.6 to convert the price to cents per BTUs.

We construct the energy price def ator as

$$
P_{t}=\sum_{i} Q_{i t} P_{i t} / \sum_{i} Q_{i t} P_{i 0} \text {. }
$$

Finally, nominal expenditure is $P_{t} \cdot E_{t}=\sum_{i} Q_{i t} P_{i t}$.

\section{A.2. Output, consumption, investment, and the capital stock}

We follow the method described by Cooley and Prescott (1995) to construct broad measures of output, consumption, investment, and the capital stock. Specif cally, our measure of capital includes private stock of capital, the stock of inventories, the stock of consumer durable goods and the government stock. Consequently, the measured value of GDP is augmented with the imputed f ow of services from the stock of durable goods and the government stock. For output, investment, and capital we subtract from each of these series the corresponding series for the energy producing sector.

To calculate the output of the energy sector, we sum the value added of the coal, petroleum, electricity and natural gas sectors. Value added of each sector is assumed to be equal to value of domestic production of that sector. The series of domestic production are in the AER (Table 5.1 for oil; Table 6.1 for natural gas; Table 7.2 for coal; and Table 8.1 for electricity). Real gross output is the sum of value added and the expenditure on energy. The investment in the energy sectors is def ned as the sum of total investment in sectors def ned as coal mining, oil and gas extraction, and electric and gas services. Similarly, we have subtracted from the aggregate capital stock that corresponding to the sectors mentioned. The data used for these series is the historical data on investment and net stock by industry that can be accessed in the NIPA page.

\section{Appendix B. Competitive equilibrium}

\section{B.1. A plant manager's problem}

Let us denote by $\Omega_{t}^{*}=\left\{K_{t}, A_{t}\right\}$ the information set available to the manager at the time of choosing the amount of capital to be located at the plant, before the energy price $p_{t}$ and the idiosyncratic technology shock $s_{t}$ are realized, and let $\Omega_{t}=\Omega_{t}^{*} \cup\left\{p_{t}\right\}$. Therefore, the plant manager's problem is

$$
\max _{k_{t}, a_{t}} E\left\{E \left[\max _{h\left(s_{t}\right) \in\{0,1\}}\left[\left(s_{t}+z\right) B k_{t}^{\theta}-w_{t}-p_{t} \gamma \frac{k_{t}}{a_{t}} h\left(s_{t}\right)\left|\Omega_{t}-r_{t}^{k} k_{t}-r_{t}^{a} a_{t}\right| \Omega_{t}^{*}\right\} .\right.\right.
$$


The expression inside the straight brackets shows the problem that the plant's manager solves once the energy price and the idiosyncratic shock are revealed. The decision is whether to operate the plant or not. Taking into account that the plant will not operate for low values of the technology shock, the plant's manager chooses the amount of productive and technological capital that maximizes expected profi conditional on $\Omega_{t}^{*}$; that is, before the energy price and the idiosyncratic technology shock are known.

\section{B.2. The measure of plants}

Let us call $\Pi\left(K_{t}, A_{t}, k_{t}, a_{t}\right)$ the maximum value of the expected proft given in expression (B.1). Since all plants are ex-ante identical, all of them will use the same amount of capital and hence, in equilibrium, $k_{t}=K_{t} / m_{t}$ and $a_{t}=A_{t} / m_{t}$. Since the cost of establishing a new plant is zero, it follows that the number of plants at the beginning of period $t, m_{t}$, is that for which

$$
\Pi\left(K_{t}, A_{t}, \frac{K_{t}}{m_{t}}, \frac{A_{t}}{m_{t}}=0 .\right.
$$

The number (measure) of plants is well determined since capital has to be paid for independently of the plant being operated or not. Therefore, at the time the idiosyncratic shock is realized, capital cost is a f xed cost from the viewpoint of the plant. The existence of this fi ed cost is what prevents the measure of plants from being infi ite.

\section{B.3. The household's problem}

$$
\max E_{0}^{\infty} \beta^{t}\left(\log c_{t}+\alpha \log \left(1-h_{0}\right) \pi_{t}\right)
$$

subject to (15) and (16) and

$$
c_{t}+X_{k t}+X_{a t}\left[1+g\left(\frac{X_{a t}}{A_{t}} \leqslant w_{t} \pi_{t} h_{0}+r_{k t} K_{t}+r_{a t} A_{t}+D_{t} .\right.\right.
$$

Aggregate realized dividends in this economy are

$$
D_{t}=\left[\left(z+\sigma\left(1-n_{t}\right)\right) n_{t} B k_{t}^{\theta} h_{0}-w_{t} n_{t} h_{0}-p_{t} \gamma \frac{k_{t}}{a_{t}} n_{t} h_{0}-r_{k t} k_{t}-r_{a t} a_{t} m_{t} .\right.
$$

\section{B.4. Equilibrium}

Def nition 1. An equilibrium for this economy, given $\left\{p_{t}\right\}$, is an allocation $\left\{c_{t}, \pi_{t}, K_{t+1}\right.$, $\left.A_{t+1}, m_{t}, n_{t}\right\}$, function $h(s)$ and a vector of prices $\left\{w_{t}, r_{k t}, r_{a t}\right\}$ such that

(i) $\left\{K_{t} / m_{t}, A_{t} / m_{t}, h(s)\right\}$ solve (B.1) given the prices $\left\{p_{t}, w_{t}, r_{k t}, r_{a t}\right\}$,

(ii) $h(s)=h_{0}$ for all $s \geqslant s\left(K_{t}, A_{t}, p_{t} m_{t}\right)$ and zero otherwise, and the fraction of operated plants satisfie $n_{t}=\left(\sigma-s\left(K_{t}, A_{t}, p_{t} m_{t}\right)\right) / 2 \sigma$,

(iii) the number of plants $m_{t}$ satisfie (B.2), 
(iv) $\left\{c_{t}, \pi_{t}, K_{t+1}, A_{t+1}\right\}$ solves the household's problem given the prices $\left\{p_{t}, w_{t}, r_{k t}, r_{a t}\right\}$, and

(v) the labor market clears, $\pi_{t}=m_{t} n_{t}$, for all $t$.

\section{References}

Atkeson, A., Kehoe, P.J., 1999. Models of energy use: putty-putty versus putty-clay. American Economic Review 89 (4), 1028-1043.

Berndt, E.R., Wood, D.O., 1975. Technology, prices and the derived demand for energy. Review of Economics and Statistics 57 (3), 259-268.

Bresnahan, T.F., Ramey, V.A., 1993. Segments shifts and capacity utilization in the US automobile industry. American Economic Review 83 (2), 213-218.

Cooley, T.F., Hansen, G.H., Prescott, E.C., 1995. Equilibrium business cycles with idle resources and variable capacity utilization. Economic Theory 6, 39-45.

Cooley, T.F., Prescott, E.C., 1995. Economic growth and business cycles. Chapter 1 in: Cooley, T.F. (Ed.), Frontiers of Business Cycle Research. Princeton Univ. Press, Princeton. .

Davis, S.J., Haltiwanger, J., 1999. Sectoral job creation and destruction responses to oil price changes. NBER working paper 7095 .

Doms, M.E., Dunne, T., 1993. Energy intensity, electricity consumption, and advanced manufacturing technology usage. Center for Economic Studies working paper 93-9. UU Bureau of the Census.

Finn, M.G., 1996. Variance properties of Solow's productivity residual and their cyclical implications. Journal of Economic Dynamics and Control 19 (57), 1249-1281.

Goulder, L.H., 1992. Carbon tax design and US industry performance. Chapter 6 in: Poterba, J.M. (Ed.), Tax Policy and the Economy, vol. 6. MIT Press, Cambridge, MA.

Goulder, L.H., 1993. Energy taxes: Traditional eff ciency effects and environmental implications. NBER working paper 4582.

Goulder, L.H., 1995. Effects of carbon taxes in an economy with prior tax distortions: an intertemporal general equilibrium analysis. Journal of Environmental Economics and Management 29 (3), 271-297.

Griff n, J.M., Gregory, P.R., 1976. An intercountry translog model of energy substitution responses. American Economic Review 66 (5), 845-857.

Hamilton, J.D., 1988. A neoclassical model of unemployment and the business cycle. Journal of Political Economy 96 (3), 593-617.

Hansen, G.D., 1985. Indivisible labor and the business cycle. Journal of Monetary Economics 16, 309-318.

Jorgenson, D.W., Wilcoxen, P.J., 1993. Reducing US carbon emissions: An econometric general equilibrium assessment. Resource and Energy Economics 15 (1), 7-25.

Juillard, M., 1997. Dynare: A program for the resolution and simulation of dynamic models with forward variables through the use of a relaxation algorithm. CEPREMAP working paper 9602.

Kim, I.M., Loungani, P., 1992. The role of energy in real business cycle models. Journal of Monetary Economics 29 (2), 173-189.

Newell, R.G., Jaffe, A.B., Stavins, R.N., 1999. The induced innovation hypothesis and energy-saving technological change. Quarterly Journal of Economics 114 (3), 941-975.

Pindyck, R.S., 1991. Interfuel substitution and the industrial demand for energy: an international comparison. Review of Economics and Statistics 29 (2), 173-189.

Pindyck, R.S., Rotemberg, J.J., 1983. Dynamic factor demands and the effects of energy price shocks. American Economic Review 73 (5), 1066-1079.

Rogerson, R., 1988. Indivisible labour lotteries and equilibrium. Journal of Monetary Economics 21, 3-16.

Rotemberg, J.J., Woodford, M., 1996. Imperfect competition and the effects of energy price increases on economic activity. Journal of Money, Credit, and Banking 38 (4), 549-577.

Sakellaris, P., 1997. Irreversible capital and the stock market response to shocks in prof tability. International Economic Review 58 (2), 351-379. 